Крохичева Г. Е., Д. э. н., проф. кафедры «Экономическая безопасность, учет и право», ДГТУ, Ростов-на-Дону, Россия; galina-krokhicheva@yandex.ru;

Нелипа А.П., студент 3 курса кафедры «Экономическая безопасность, учет и право» ДГТУ, Ростов-на-Дону, Россия; nelipa98@mail.ru

\title{
ОСОБЕННОСТИ АНТИИФЛЯЦИОННОЙ ПОЛИТИКИ РФ
}

Аннотация. В данной статье рассматриваются вопросы антиинфляционной политики как важного условия его экономического роста. Выбор методов антиинфляционного воздействия должен определяться характером и уровнем инфляции, спецификой действия хозяйственного механизма. Выявлены аспекты инфляции в современной российской экономике и предложены меры антиинфляционной политики как средства комплексного воздействия на причины формирования инфляционных процессов.

Ключевые слова: инфляция; антиинфляционная политика; дезинфляция; фискальная политика; гипотеза естественного уровня;

Krokhicheva G.E., doctor of Economic Sciences, professor "Economic security, account and right" DGTU, Rostov-on-Don, Russia; galina-krokhicheva@yandex.ru

Nelipa A.P., 3 year student of the department "Economic security, accounting and law", Don State Technical University, Rostov-on-Don, Russia; nelipa98@mail.ru

\section{FEATURES ANTI-INFLATIONARY POLICY OF THE RUSSIAN FEDERATION}

Annotation. The article is devoted to the anti-inflation policy as an important condition for its economic growth. The choice of anti-inflation impact methods of anti-inflationary impact should be determined by the nature and level of inflation, the economic mechanism specifics. The aspects of inflation in the modern Russian economy are revealed and the measures of anti-inflation policy as a means of complex influence on the reasons of inflation processes formation are offered. 
Key words: inflation; anti-inflation policy; disinflation; fiscal policy; the hypothesis of natural level;

Необходимым условием эффективной макроэкономической политики государства, обеспечивающей стабильное экономическое развитие страны, считается эффективное антиинфляционное урегулирование, так как инфляция выступает главной проблемой национальной экономики, активизирующей отрицательные социально-экономические последствия.

Наличие в государстве инфляции подразумевает необходимость корректировки индексации доходов и цен. Однако стоит отметить, что потребительские цены не корректируются постоянно, в том числе и устойчивая ожидаемая инфляция приводит к изменению относительных цен, следовательно, различные предприятия корректируют свои цены в разное время. Вследствие чего, инфляция увеличивает отклонение относительных цен от значений проводимой корректировки. $\mathrm{B}$ ряде исследований представлено, что вызванные инфляцией изменения относительных цен нарушает работу рынков, где создаются долгосрочные взаимоотношения среди экономических субъектов.

Теоретические модели также свидетельствуют о том, что инфляция способна проявлять отрицательное влияние на рыночную структуру, долговременные взаимоотношения и продуктивность, раскрывая механизмы, посредством которых инфляция способна приводить к существенным издержкам. Инфляция порождает затруднение в расчетах, а так же их неточность у хозяйствующих субъектов. Вследствие чего, домашние хозяйства и предприятия, которые как правило реализовывают финансовое планирование в номинальных единицах, имеют все шансы совершать систематические просчеты при реализации долговременных инвестиционных проектов и сбережении средств.

Негативные социально-экономические результаты инфляции вызывают потребность увеличения мер антиинфляционной политики государства. В 
первую очередь целями государственной антиинфляционной политики должны являться регулирование цен, прогнозируемость самой динамики инфляции, сокращение инфляции, а так же сокращение инфляционного потенциала. Главной целью антиинфляционной политики является послужить причиной темпа увеличения объема и структуры совокупного предложения с объемом и структурой общего спроса в долгосрочном плане, а также денежной массы в соотношение с темпами роста товарной массы в краткосрочном плане.

Типы антиинфляционной политики представлены на рисунке 1.

\begin{tabular}{|l|l|}
\hline $\begin{array}{l}\text { Типы } \\
\text { антиифляционной } \\
\text { политики: }\end{array}$ & $\begin{array}{l}\text { Фискальная политика } \\
\text { Кредитно-денежная политика }\end{array}$ \\
\cline { 2 - 3 } & $\begin{array}{l}\text { Монетаризм } \\
\text { Гипотеза естественного уровня } \\
\text { Фискальная политика, направленная на } \\
\text { предложение }\end{array}$ \\
\hline
\end{tabular}

Рис.1 Типы антиинфляционной политики.

Фискальная политика - это манипулирование государственным бюджетом (правительственными расходами и налогообложением) с целью достижения выдвинутых целей увеличение производства и занятости или снижения инфляции. Либеральные экономисты, которые полагают, что государственный сектор должен быть расширен, для того, чтобы возместить разнообразные погрешности рыночной системы, советуют ограничение совокупных расходов в промежуток роста инфляции за счет увеличения налогов. Консервативные экономисты, считающие, что государственный сектор чрезмерно раздут и неэффективен, могут выступать за сокращение расходов в период роста инфляции за счет сокращение государственных 
расходов. Активная фискальная политика, нацеленная на стабилизацию экономики, может опираться на расширяющийся, так и на сокращающийся государственный сектор.

В кредитно-денежной политике для того чтобы сдержать инфляционное давление и снизить расходы с целью ограничения предложения денег, применяется политика дорогостоящих денег. Её роль состоит в снижении резервов коммерческих банков. Она производится следующим методом, представленном на рисунке 2.
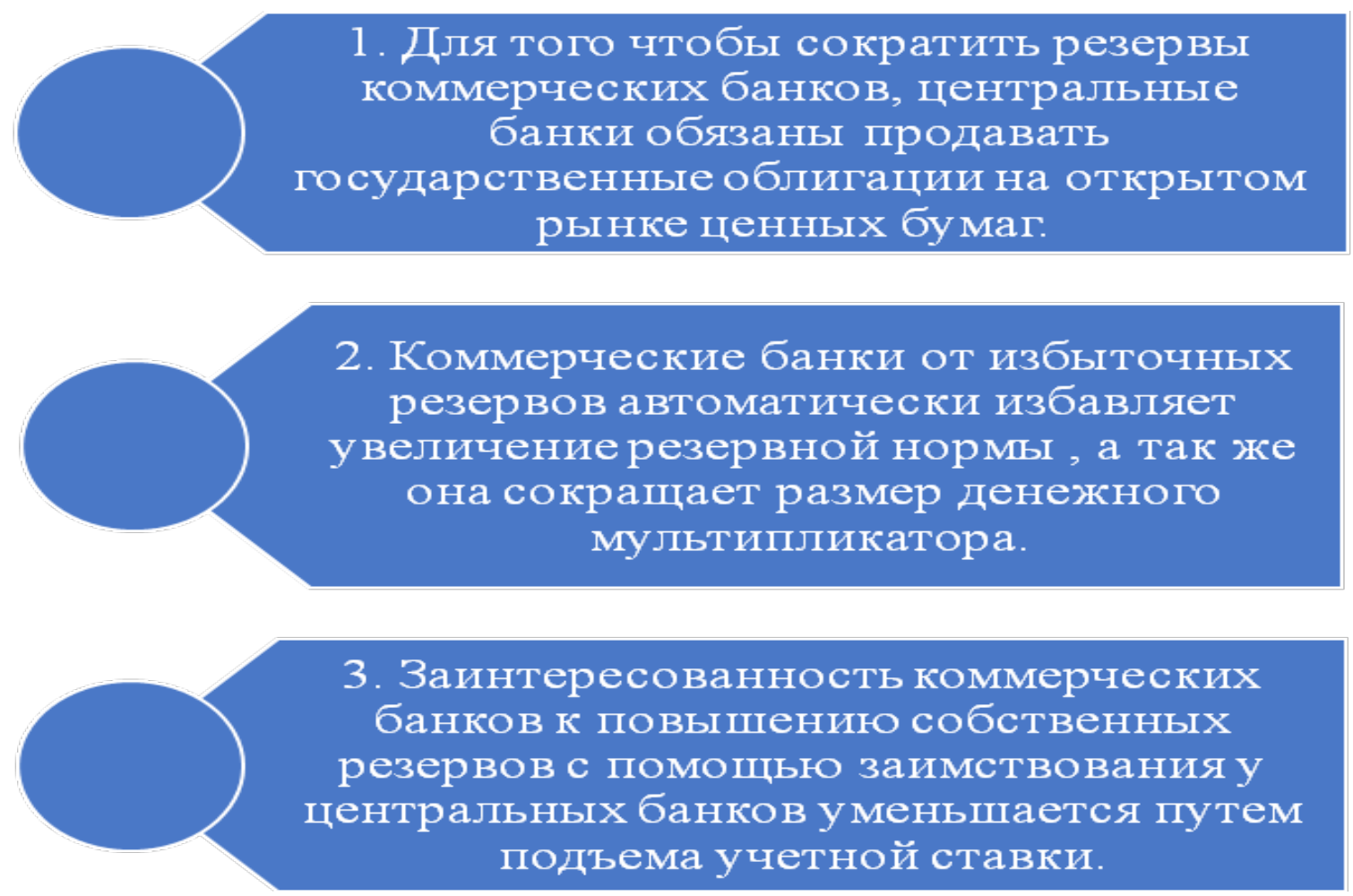

Рис.2. Метод кредитно-денежной политики

Гипотеза естественного уровня заключается в утверждении, что при естественном уровне безработицы, экономика считается стабильной в долгосрочном плане.

Гипотеза естественного уровня имеет два варианта:

1. Теория адаптивных ожиданий. Главная мысль данной теории заключается в том что весь вид адаптационных ожиданий сводится к тому, что люди представляют будущее аналогично прошлому, т.е они отталкиваются от него 
и сформировывают свои собственные планы, следовательно фирмы ожидают в текущем году тот же темп инфляции, что и в прошлом. Зачастую в более сложных экономических моделях, подразумевается, что надежды базируются на некоем средневзвешенном значении темпов обесценивания денежных единиц за несколько предыдущих лет. Теория адаптивных ожиданий подразумевает в своей основе применение кривой совокупного предложения, которая в свою очередь имеет положительный наклон в краткосрочном временном интервале, а так же перемещающуюся вверх в долгосрочном. В таком случае формируется вполне пригодная для интерпретации инфляционного процесса основа. При всем этом следует заметить, что по ряду причин, данная теория не удовлетворяет множество экономистов.

2. Теория рациональных ожиданий. В данной теории следует выделить ее главное положение, что рынки факторов производства и товаров считаются высококонкурентными, а по этой причине цены на товары, факторы производства и ставки заработной платы гибко реагируют на перемены в сфере обмена и производства. Предприниматели и потребителя попадающие под влияние новой рыночной ситуации принимают определенные экономические решения, вследствие чего цены на ресурсы, а также на товары изменяются. Результаты стабилизационной политики при такой реакции предпринимателей, собственников факторов производства и потребителей сводятся на нет.

Фискальная политика имеет направленность на предложение. Такая политика способна изменить совокупное предложение, из чего следует, что она так же повлияет и на те изменения, которые фискальная политика может вызвать в соотношении уровень цен - реальное производство. Увеличение размеров доходов после уплаты налогов будет вызвано более низкой ставкой самих налогов и как следствие, таким образом увеличат сбережения домашних хозяйств.

Прибыльность инвестиций повысится за счет снижения налогов на предпринимателей. Более того, сокращенные подоходные налоги, 
стимулируют работников к труду за счет повышения заработной платы после уплаты налогов. Если же обратить внимание на подобную экономическую ситуацию со стороны традиционных кейнсианских подходов, уменьшение налоговых ставок, в этой ситуации, вызывает увеличение дефицита бюджета и уменьшение налоговых поступлений, подход экономики предложения предполагает, что она обеспечит рост налоговых поступлений с сокращение дефицитов.

Мероприятия, направленные на антиинфляционное влияние, необходимо осуществлять совокупно т.е комплексно, в зависимости от сформировавшейся макроэкономической ситуации, а также с учетом превалирующего типа инфляции.

В частности, в случае если экономика государства характеризуется доминированием факторов инфляции спроса, мерами снижения темпов роста общего уровня цен могут стать повышение ключевой ставки и нормы обязательного резервирования, лимитирование роста предложения денег, повышение налоговой ставки, снижение государственных расходов, но при условии, что сама экономика страны функционирует в условиях полной занятости. Впрочем, в экономике Российской Федерации подобная стратегия окажется неэффективной, поскольку характеризующую роль в формировании инфляционных процессов выступают факторы инфляции издержек и прослеживается неполноценное использование производственных мощностей.

Принимая во внимание характерные признака формирования инфляционных процессов в государстве, можно заявлять, то, что выполнение результативной антиинфляционной политики не представляется допустимым без использования антимонопольных мер, которые помимо содействия формированию конкурентной борьбы и совершенствования структуры рынка будут регулировать деятельность монополий. В современных экономических условиях главным регулятором хозяйственных процессов стает антимонопольное законодательство, которое, в свою очередь, обязует 
способствовать тому, чтобы в условиях конкурентной борьбы сформировалась справедливая цена.

\section{Список литературы:}

1. Кабир Л.С. Инновационная деятельность и поддержка инвестиций: изменения в налоговой политике на современном этапе // Теория и практика общественного раз- вития. 2016 №3. С. 39-42

2. Киселева П.С., Ильяшенко В.В. Факторы и динамика инфляционных процессов в промышленном регионе //Известия Уральского государственного экономического университета. 2015. №3 (59). С. 24-29

3. Смирнов С.В., Кондрашов Н.В., Петроневич А.В. Поворотные точки российского экономического цикла, 1981-2015 гг. // Экономический журнал ВШЭ. 2015№4. Т. 19. С. 534-553.

4. Сомова И.А. Таргетирование инфляции в России // Вестник Новосибирского государственного университета. Сер.: Социальноэкономические науки. 2014. №2. С. 5-12

5. Темп инфляции РФ за 2014-2016 г.г., [Электронный ресурс]. URL:http://www.cbr.ru/

6. Матвеева Т.Ю. "Макроэкономика: Курс лекций для экономистов", 2014 Г., [Электронный ресурс].

\section{URL:http://www.ereport.ru/articles/macro/macro14.htm}

References:

1. Kabir L. S. Innovation and investment support: changes in tax policy at the present stage // Theory and practice of social development. 2016 №3. P. 39-42

2. S. P. Kiselev, V. V. Ilyashenko factors on the dynamics of inflationary processes in the industrial region//news of the Ural state economic University. 2015. №3 (59). C. 24-29

3. Smirnov S. V., Kondrashov N. In. Petronevich A. V. Turning points of the Russian economic cycle, 1981-2015. / / HSE Economic journal. 2015 No. 4. Vol. 19. P. 534-553. 
4. I. Somova inflation Targeting in Russia / / Vestnik Novosibirsk state University. Ser.: Social and economic Sciences. 2014. No. 2. P. 5-12

5. Inflation rate of the Russian Federation for 2014-2016, [Electronic resource]. URL: http: / / www.cbr.EN/

6. Matveeva T. " macroeconomics: a course of lectures for economists, 2014, [Electronic resource]. URL:http://www.ereport.ru/articles/macro/macro14.htm 